\title{
Exploring the limits of morphospace: Ontogeny and ecology of late Viséan ammonoids from the Tafilalt, Morocco
}

Christian Klug, Kenneth De Baets, and Dieter Korn

Acta Palaeontologica Polonica 61 (1), 2016: 1-14 doi:http://dx.doi.org/10.4202/app.00220.2015

Early late Viséan ammonoid assemblages in Morocco are composed of diverse and well-preserved specimens. The material was found in a plain in the Tafilalt (eastern Anti-Atlas). Here, we describe mass-occurrences of juvenile specimens, in which subadult and adult specimens occur in low numbers. The juveniles of some species display a conch morphology that differs fundamentally from the adult stages. Accordingly, we emend the species diagnoses of Goniatites lazarus as well as Calygirtyoceras darkaouaense, introduce the species Entogonites bucheri sp. nov., and discuss possible ecological implications of the morphologic changes throughout ontogeny. In particular, we compare the changes in conch morphology through ontogeny in the light of Pareto Optimiality according to which the morphology of organisms would fill a polygon or polyhedron in morphospace. Data points in one of the vorteces of the polyhedron indicate optimisation for the corresponding task. Although shape is not a proof of function, it appears plausible that juvenile conchs were selected rather for compactness while adult conchs were positively selected for conchs with improved hydrodynamic properties. This appears plausible because at small conch diameters, swimming movements will not suffice for effective translocation and a planktonic mode of life is likely.

Key words: Ammonoidea, morphospace, palaeoecology, Viséan, Morocco.

Christian Klug [chklug@ pim.uzh.ch], Paläontologisches Institut und Museum der Universität Zürich, Karl Schmid-Str. 4, CH-8006 Zürich, Switzerland. Kenneth DeBaets [kenneth.debaets@fau.de], GeoZentrum Nordbayern, Friedrich-Alexander-Universität Erlangen-Nürnberg, Loewenichstraße 28, D-91054 Erlangen, Germany. Dieter Korn [dieter.korn@mfn-berlin.de], Museum für Naturkunde Berlin, Leibniz-Institut für Evolutions- und Biodiversitätsforschung, Invalidenstraße 43, D-10115 Berlin, Germany. 
Attribution License (for details please see creativecommons.org), which permits unrestricted use, distribution, and reproduction in any medium, provided the original author and source are credited.

Fof Full text $(1.552 .1 \mathrm{kB})$ 